\title{
A prática de revisão textual na escola: uma análise das categorias de correção em uma oficina de fanfictions
}

\section{The text review practice at school: an analysis of the revision categories in a fanfiction workshop}

Larissa Giacometti Paris*

*Universidade Estadual de Campinas (Unicamp), Campinas, São Paulo / Brasil larissagparis@gmail.com

RESUMO: O objetivo deste trabalho consiste em analisar três aspectos referentes às revisões realizadas por alunos nos textos de seus colegas em uma oficina de fanfictions no ambiente escolar: o uso da correção indicativa no contexto digital; a correção resolutiva/textual-interativa e seu caráter polifônico; e o emprego da correção textual-interativa pelos discentes que se posicionaram como leitores interessados. As análises foram baseadas nas discussões desenvolvidas por Serafini (1995) e Ruiz (1998), para refletir sobre a prática de revisão, e na teoria de Bakhtin, acerca da questão do dialogismo. Foi possível constatar que tanto o instrumento pode interferir na prática e na função das categorias de correção, como a prática pode ser fator de interferência no instrumento e na função das categorias.

PALAVRAS-CHAVE: revisão; categorias de correção; dialogismo; escola; fanfictions.

\begin{abstract}
This paper aims to analyze three aspects regarding revisions made by students in their classmates' texts in a fanfiction workshop held in the school context: the use of indicative correction in the digital context; the resolutive/textual-interactive correction and its polyphonic feature; and the use of textual-interactive correction by students who have positioned themselves as interested readers. This analysis is based on discussions about text review practice held by Serafini (1995) and Ruiz (1998) and in Bakhtin's theory on the issue of dialogism. Thereby, it was found that the instrument may interfere with the practice and with the function of revision categories, and also that the practice may interfere with the instrument and with the function of those categories.
\end{abstract}

KEYWORDS: text review; revision categories; dialogism; school; fanfictions. 


\section{Introdução}

As práticas de revisão e reescrita no ambiente escolar são objeto de estudo de muitas pesquisas atualmente (CONCEIÇÃO, 2004; FIAD, 2006; GONÇALVES, 2010; GONÇALVES; BAZARIM, 2013; MENEGASSI, 2003, 2011; SARTORI; MENDES, 2016; entre outros). Há diferentes abordagens teóricas que buscam refletir sobre a produção escrita dos alunos, o que torna a discussão bastante complexa e diversificada. Por outro lado, tal variedade pode fornecer ao professor e à escola uma gama de alternativas não sendo entendidas aqui como meramente soluções prontas - em relação às dificuldades de ensino e aprendizagem da produção escrita.

Partindo dessa perspectiva, contemplo a discussão neste artigo como uma alternativa, entre muitas outras possíveis, para se pensar na prática de revisão, compreendida aqui como uma etapa essencial para a produção escrita. Assim, busco atrelar a revisão do contexto escolar ao digital, na medida em que analiso alguns dados gerados em uma oficina de produção de fanfictions realizada na escola.

Portanto, o objetivo deste artigo é analisar parte do corpus gerado a partir da referida oficina, que serviu como base para uma pesquisa de mestrado $^{1}$ já finalizada. Mais especificamente, pretendo refletir sobre determinados aspectos particulares que se relacionaram à prática de revisão dos textos escritos pelos alunos e posteriormente revisados por seus próprios colegas: a) o emprego da correção indicativa no contexto digital, b) a utilização de uma nova categoria de correção - denominada por mim como resolutiva/textual-interativa - e seu caráter polifônico e, finalmente, c) o uso da correção textual-interativa pelos sujeitos que se posicionaram como leitores interessados.

Entretanto, em um primeiro momento, é preciso definir brevemente as fanfictions e situá-las considerando a sua escrita como uma prática social, para que, em um segundo momento, seja possível analisar parte do corpus gerado a partir da oficina.

Black (2006) define as fanfictions como histórias de universos ficcionais já existentes escritas por seus fãs, que deles se utilizam como

\footnotetext{
${ }^{1}$ Pesquisa de mestrado desenvolvida no programa de pós-graduação em Linguística Aplicada do Instituto de Estudos da Linguagem da Universidade Estadual de Campinas (IEL/Unicamp), sob orientação da Profa. Dra. Raquel Salek Fiad.
} 
inspiração para produzir seus próprios textos. Em outras palavras, a autora afirma que

fanfiction, ou histórias de autoria de um fã baseadas em conteúdos midiáticos já existentes, é um gênero que se presta a um engajamento crítico em relação aos textos midiáticos na medida em que os fãs redirecionam tais conteúdos para criar suas próprias narrativas. ${ }^{2}$ (BLACK, 2010, p. 76, tradução minha)

As narrativas geralmente são baseadas em livros, filmes, séries de televisão, animações ou desenhos, ícones da cultura pop (como atores, cantores, bandas etc.), entre outros. Desse modo, há apropriação do texto do outro, embora o fã escritor tenha a liberdade de criar novos personagens, desenvolver novas relações entre eles, acrescentar ou transformar acontecimentos da trama, dar maior ênfase a personagens secundários (BLACK, 2006, 2008), entre outras possibilidades. Fica claro, então, que se escrevem novas narrativas, ainda que estas sejam baseadas em um universo ficcional já existente.

Nesse sentido, a escrita de fanfictions se insere no contexto da cultura participativa, termo cunhado por Jenkins $(1992,2006)$ ao observar o universo de fãs desde meados da década de 1970. De acordo com o autor, "os fãs deixam de ser simplesmente uma audiência para os textos populares; ao invés disso, eles se tornam participantes ativos na construção e circulação dos sentidos textuais"3 (JENKINS, 1992, p. 24, tradução minha). Em uma cultura participativa, então, todos os fãs são considerados potenciais escritores, o que acarreta em uma mudança de posicionamento de leitores para também produtores de narrativas sobre os livros, filmes e séries que admiram, considerando que esses sujeitos não se limitam somente a consumir determinado conteúdo.

Para Jenkins (2006), a passividade dos espectadores em relação aos meios de comunicação não condiz com o contexto social contemporâneo constitutivo de uma cultura participativa, levando em conta que a separação

\footnotetext{
${ }^{2}$ No original: "Fanfiction, or fan-authored stories based on existing media, is a genre that lends itself to critical engagement with media texts as fans repurpose these media to create their own narratives."

${ }^{3}$ No original: "Fans cease to be simply an audience for popular texts; instead, they become active participants in the construction and circulation of textual meanings."
} 
de papéis entre produtor e consumidor está cada vez mais fluida. É a partir dessa perspectiva que podemos considerar a escrita de fanfictions como parte de uma cultura participativa, já que os sujeitos leitores/espectadores decidem escrever suas próprias narrativas a partir de um universo ficcional já existente, tornando-se também escritores/produtores.

Em relação ao seu contexto de produção, é válido ressaltar que as fanfictions podem ser publicadas em sites específicos de publicação e compartilhamento on-line de tal gênero. De acordo com Black (2005), os sites de publicação de fanfictions são considerados bons exemplos da tecnologia constituindo-se como suporte para os usos significativos da linguagem - por meio dos espaços destinados à interação explícita entre escritores e leitores - que são fundamentais para todos os estudantes em suas práticas de letramentos no contexto escolar. A autora ainda afirma que

embora a ideia de acrescentar atividades de produção escrita autênticas ao currículo não seja nova, as possibilidades que os ambientes de computação em rede oferecem para o desenvolvimento de atividades de escrita autênticas e interativas nas salas de aula são novas em muitos aspectos. $^{4}$ (BLACK, 2005, p. 126, tradução minha)

Uma dessas possibilidades, segundo Black, relaciona-se com a presença de sujeitos que se dispõem a revisar voluntariamente as fanfictions de usuários desses sites. Nesse contexto, o revisor é denominado de betareader. O nome é resultante da ideia de que o escritor, sendo a primeira pessoa a ler a fanfiction, seria o alpha-reader, e o revisor, suposta segunda pessoa a lê-la, o beta-reader, considerando que alpha e beta são letras sucessivas do alfabeto grego.

Assim, em alguns sites de publicação de fanfictions, é comum que os moderadores peçam aos participantes que solicitem um beta-reader para revisar sua narrativa antes de publicá-la (BLACK, 2005). É importante ressaltar que o revisor geralmente é também um escritor de fanfictions, tornando a prática em uma revisão entre pares, isto é, entre sujeitos que ocupam posições hierárquicas simétricas. Nesse sentido, Black (2005) afirma que a revisão entre pares nas comunidades de publicação de fanfictions é

\footnotetext{
${ }^{4}$ No original: "While the idea of adding authentic composition activities to the curriculum is not new, the possibilities that networked computer environments offer for developing authentic, interactive writing activities in the classroom are novel in many ways."
} 
compreendida como uma prática significativa para aprimorar a produção escrita do sujeito escritor, fazendo com que ele não se sinta intimidado ou constrangido ao ter sua narrativa revisada por outro sujeito, já que o revisor é reconhecido como um par.

Para a autora, a revisão entre pares revela uma forte tendência da comunidade em construir e manter relações sociais por meio de críticas "com entusiasmo genuíno pelo conteúdo ou efeito retórico, desencorajando fortemente o feedback hostil"5 (BLACK, 2005, p. 127, tradução minha). Nesse tipo de relação, segundo Jenkins (2006), tanto o "aprendiz" é favorecido, ao construir novos conhecimentos, quanto o outro "par" também é beneficiado, já que se sente como um especialista enquanto está ensinando. Jenkins ainda afirma que, em uma comunidade de fãs, os papéis sociais são fluidos, por se tratar de um contexto sociocultural flexível, e alternam-se constantemente, considerando que o mesmo sujeito que ensina em determinada situação pode aprender em outra com o auxílio de uma pessoa diferente (JENKINS, 2006).

Considerando que, no ambiente escolar, a reescrita é vista pelos alunos como uma obrigação e, muitas vezes, como uma perda de tempo, é interessante refletir que, de modo contrário, no contexto de publicação de fanfictions tal prática seja compreendida como uma etapa do processo de produção do texto. Assim, a revisão permite que a prática de reescrita pouco comum na escola - seja realizada também de modo voluntário pelo escritor após receber o retorno de seu beta-reader. É possível concluir que a reescrita das fanfictions é uma prática valorizada pelos seus escritores por assumirem um lugar como sujeitos que possuem um interlocutor com quem dialogar. Isto é, os beta-readers agem como verdadeiros parceiros e interlocutores, na medida em que na escrita, e também na reescrita desse gênero discursivo, um dos pressupostos fundamentais é a presença de um interlocutor autêntico e de um objetivo claro para escrever.

\section{Metodologia de pesquisa: a oficina de produção de fanfictions}

A pesquisa que resultou na produção deste artigo constitui-se como qualitativa de base interpretativista e insere-se nas investigações

\footnotetext{
${ }^{5}$ No original: "With genuine enthusiasm for content or rhetorical effect, strongly discouraging hostile feedback."
} 
contempladas pela linguística aplicada. Partindo dessa perspectiva, é interpretativista porque cada pesquisador gera e analisa seus dados de modo subjetivo, por mais que haja a intenção de objetividade típica de investigações científicas, conforme afirma Thiollent (2011).

Para a geração de dados, uma oficina de produção escrita de fanfictions foi realizada em uma escola de uma cidade do estado de São Paulo pertencente à rede privada. A oficina foi ministrada uma vez por semana, no período contraturno ao das aulas regulares, com duração de uma hora, durante o segundo semestre de 2014, totalizando 15 aulas, todas gravadas em áudio. A oficina foi realizada no laboratório de informática da escola, havendo um computador para cada aluno, distribuídos em semicírculo.

A participação dos alunos foi voluntária, e a maioria cursava o primeiro ano do ensino médio. Ao todo, oito discentes foram considerados sujeitos da pesquisa, sendo selecionados os estudantes que participaram até o encerramento da oficina. Em uma conversa que tiveram comigo em nosso primeiro encontro, todos os alunos afirmaram que já haviam escrito ou ao menos lido fanfictions. Eu, como pesquisadora, também fui responsável por fazer o acompanhamento das aulas como professora.

No decorrer da oficina, cada aluno exerceu os papéis de escritor de seu próprio texto e de revisor do texto de um colega, configurando-se como uma revisão entre pares similar ao contexto de produção e publicação de fanfictions. Assim, a cada semana, os estudantes escreviam um capítulo de suas histórias em casa, que era revisado por outro aluno em sala de aula e, posteriormente, reescrito pelo escritor. O universo ficcional que serviu de base para a produção das narrativas foi de livre escolha de cada sujeito.

Não houve planejamento prévio dos conteúdos a serem trabalhados na oficina. A cada semana, conforme eu lia as revisões e reescritas dos alunos, realizava apenas algumas atividades com os estudantes que, em sua maioria, constituíam-se por revisões coletivas de fanfictions publicadas na internet. As revisões coletivas se justificam na medida em que eu, como pesquisadora, não queria que houvesse alguma alteração direta feita por mim nos textos específicos dos sujeitos da pesquisa. O objetivo era que somente os próprios colegas revisassem as fanfictions um do outro.

Para a escrita, revisão e reescrita das fanfictions, os discentes fizeram uso do processador de texto Word e de sua respectiva ferramenta de revisão, a partir de uma sugestão minha. Assim, evitamos que houvesse limitações de espaço para a escrita dos comentários de revisão. É válido ressaltar que não 
houve interferências de minha parte em relação ao conteúdo ou aos aspectos textuais e discursivos que deveriam ou não ser revisados em cada narrativa. Somente orientei como fazer uso dos recursos presentes na ferramenta de revisão do Word. Nas atividades de revisão coletiva, os alunos eram os responsáveis por fazer as correções de algumas fanfictions publicadas na internet, sendo a minha função a de mediar tais correções.

O corpus para a análise, desse modo, constitui-se pelos textos produzidos pelos alunos participantes da oficina: as primeiras versões das fanfictions, as revisões realizadas a partir delas e as versões reescritas posteriormente. Contudo, considerando o foco deste artigo, somente analisarei alguns dados referentes à prática de revisão.

Vale também ressaltar que esta pesquisa foi aprovada pelo Comitê de Ética da Unicamp sob parecer de número 669.887, datado do dia 27/05/2014. Os responsáveis pelos sujeitos - menores de idade - assinaram o Termo de Consentimento Livre e Esclarecido (TCLE) e autorizaram o uso das produções escritas de seus filhos para fins científicos. Os participantes também autorizaram a reprodução de seus textos.

Tanto o estudo de caso quanto a pesquisa-ação foram utilizados como métodos para a geração do corpus. O estudo de caso, de acordo com André (2005), focaliza uma situação ou fenômeno singular dentro de circunstâncias específicas. Assim como o próprio nome sugere, analisa-se um caso particular em que o interesse do pesquisador se relaciona com aquilo que a conjuntura tem de único e de valor em si mesmo (LÜDKE; ANDRÉ, 1986), além de ser bem delimitado e contextualizado em tempo e lugar (CHIZZOTTI, 2008). Esse é o caso da oficina de fanfictions, em que as práticas de revisão e reescrita constituíram-se como foco da investigação, sendo, portanto, uma análise contextualizada dos dados gerados.

O estudo de caso, contudo, não abrange uma parte desta pesquisa, que envolve a intervenção dos alunos participantes nas fanfictions uns dos outros. Assim, julguei ser necessário fazer uso também da pesquisa-ação para o contexto desta investigação. Segundo Thiollent (2011), em uma pesquisa-ação, há participação ativa do pesquisador e dos participantes de modo cooperativo ou participativo em relação à ação proposta, em que os sujeitos de pesquisa de fato tenham algo a dizer ou a fazer e também sejam indivíduos escolhidos de acordo com sua representatividade social em função da situação a ser transformada. Nesse sentido, une-se a pesquisa à ação, isto é, à prática. Considerando que os próprios alunos participantes da 
oficina - e, portanto, escritores e revisores - são sujeitos ativos fundamentais e socialmente representativos para as intervenções que resultaram no corpus, a pesquisa-ação revelou-se adequada a tal propósito.

\section{A prática de revisão situada no contexto da oficina: um novo olhar sobre as categorias de correção}

No livro Como escrever textos?, Serafini (1995) sistematiza os modos de se corrigir um texto em três categorias denominadas correção indicativa, resolutiva e classificatória. Para a autora, tais categorias são geralmente utilizadas por professores ao se posicionarem como revisores das produções escritas de seus alunos. Ruiz (1998), em sua tese de doutorado intitulada Como se corrige redação na escola, complementa a teoria de Serafini (1995) ao apresentar uma quarta categoria de correção empregada por professores no contexto escolar: a textual-interativa.

Para este artigo, apresento algumas análises qualitativas sobre as correções indicativa, resolutiva e textual-interativa, por terem sido aquelas que foram mais utilizadas pelos alunos ao revisar as fanfictions de seus colegas. Nesse sentido, apresento um novo olhar reflexivo sobre tais categorias. Na primeira parte desta seção, discorro sobre o uso da correção indicativa no contexto digital. Em seguida, realizo uma breve retomada teórica acerca das correções resolutiva e textual-interativa, a fim de apresentar uma nova categoria observada por mim a partir do corpus desta pesquisa: a correção resolutiva/textual-interativa, juntamente com seu caráter polifônico. Por fim, na terceira parte, discuto sobre o modo como alguns sujeitos revisores fizeram uso da correção textual-interativa nas situações em que se posicionaram como leitores interessados (BLACK, 2005) ao revisar as narrativas de seus pares.

\subsection{A correção indicativa no contexto digital}

De acordo com Serafini, a correção indicativa consiste em "marcar junto à margem as palavras, frases e períodos inteiros que apresentam erros ou são poucos claros" (1995, p. 113), por meio de uma mera indicação daquilo que deverá ser reconstruído pelo estudante. Para a autora, há risco de o aluno não ser capaz de compreender a natureza do "erro" apontado pelo professor - uma vez que esta correção é localizada, específica e pouco 
precisa - e, consequentemente, não saber como solucionar o problema indicado no texto.

A partir do corpus gerado para uma pesquisa de doutorado, Ruiz (1998) comprovou que a correção indicativa foi a mais utilizada pelos sujeitos professores ao revisarem os textos de seus alunos, embora não haja algum tipo de alteração no texto no momento da correção nas situações em que essa categoria é empregada. Gonçalves (2007) explica que a correção indicativa, na maioria dos casos, é a mais encontrada nas revisões realizadas pelos docentes provavelmente por ser a mais fácil de ser efetuada, considerando que seu objetivo é sair à caça dos erros sem se preocupar em alterar o texto ou propor sugestões de melhorias. Vale lembrar que ambas as pesquisas de Ruiz e de Gonçalves foram concretizadas por meio da análise de produções escritas, correções e reescritas realizadas no contexto do modelo impresso, assim como a de Serafini.

Além disso, Ruiz (1998) afirma que a correção indicativa não ocorre somente junto à margem do texto, como defende Serafini (1995). Para a primeira autora, apenas apontar o problema identificado - seja por meio de uma sinalização verbal ou não - na margem ou no corpo do texto já se caracteriza como correção indicativa. Gonçalves (2007) ainda comprova que esta categoria, em grande parte dos casos, privilegia somente as revisões relacionadas à norma linguística segundo a perspectiva adotada pela gramática normativa.

$\mathrm{Na}$ oficina de fanfictions, a ferramenta de revisão do Word foi utilizada pelos alunos para corrigir as narrativas de seus colegas, conforme já explicitado na seção 2 deste artigo. Entre as quatro categorias, a correção indicativa foi a única empregada em todas as revisões pertencentes ao corpus. Apresento, a seguir, duas delas:

FIGURA 1 - Revisão I

- E ir contra a vontade de minha mãe? Não seguir suas ordens?_- Ri sarcasticamente -
Não desejo a morte.

Comentário: Nãoquero morrer ou eu gosto de viver

Não quero morrer ou eu gosto de viver 
FIGURA 2 - Revisão II

- me desculpe, obrigado por salvar minha vida, agora quem é você?
- bem melhor, me chamo Dylan, pelo que me disseram você já sabe sobre
o acampamento meio sangue certo?-assenti- ótimo isso facilita muito. Sua
irmã, Annie, certo?. assenti com entusiasmo- ela chegou ao acampamento
sã e salva, e contou ao quiron o que havia acontecido com você e ele me me confuso.
mandou para te resgatar e descobrir o que estava acontecendo.

Nas revisões I e II, fica evidente que a indicação dos trechos revisados pelos alunos faz parte dos recursos oferecidos pela própria ferramenta de revisão do Word, como pode ser visto em determinadas partes do texto que foram realçadas por meio de mudanças na cor ou pelo uso do sublinhado. Em outras palavras, não houve necessidade de os estudantes empregarem correções indicativas, sabendo que, ao selecionar determinado trecho para classificar, resolver ou ainda comentar (funções das demais categorias), a indicação já era programada para ser realizada concomitantemente pela ferramenta do Word.

Considerando o contexto das correções no papel impresso, a correção indicativa é empregada deliberadamente pelo revisor. Entretanto, no contexto digital em que as revisões das fanfictions ocorreram, os alunos revisores apropriaram-se dos recursos da ferramenta para efetuar uma parte da revisão que não precisou ser elaborada por eles. Assim, não foi preciso que eles manualmente indicassem ou destacassem os trechos que necessitavam de reformulação, já que podiam fazer uso de uma ferramenta que está programada para realizar esta tarefa toda vez que alguma alteração no texto for empregada pelo revisor.

Pude constatar, portanto, que os alunos revisores usaram os recursos presentes no sistema digital a seu favor, aproveitando-se das condições mais favoráveis relacionadas ao contexto da realização da oficina para revisar as fanfictions dos seus colegas. A correção indicativa, partindo dessa situação específica, incorporou-se às demais categorias de correção e teve sua função modificada: não mais como meramente uma caça aos erros (GONÇALVES, 2007), e sim como um recurso que auxilia na localização e visualização da revisão realizada no texto.

Nesse sentido, a correção indicativa, ao ser teorizada por Serafini (1995), Ruiz (1998) e Gonçalves (2007), relaciona-se mais ao contexto do modelo impresso do que ao do digital, já que esta categoria, no papel 
impresso, pode ou não ser empregada pelo sujeito revisor, enquanto, na ferramenta digital, ela é programada para ser utilizada toda vez que esse sujeito realiza uma alteração no texto. O emprego da indicativa em todas as correções feitas pelos alunos permite concluir que o instrumento que é utilizado para a revisão também é um fator que interfere no modo como a prática é realizada e na maneira como a categoria de correção é empregada.

\subsection{A correção resolutiva/textual-interativa e seu caráter polifônico}

Nesta seção do artigo, apresento a correção resolutiva/textualinterativa, uma nova categoria teorizada a partir da análise de determinadas revisões realizadas pelos alunos no decorrer da oficina de fanfictions. Nas revisões em que tal categoria foi empregada, o caráter polifônico tornou-se evidente, embora Ruiz (1998) tenha considerado a correção resolutiva como marcadamente monológica, conforme será detalhado mais adiante.

Contudo, é preciso, em um primeiro momento, conceituar as correções resolutivas e textual-interativas para, em seguida, refletir sobre a referida categoria.

\subsubsection{A correção resolutiva}

De acordo com Serafini (1995), a correção resolutiva é utilizada nas situações em que as reformulações de palavras, períodos, frases e parágrafos são efetuadas pelo revisor do texto. A autora afirma que o professor reescreve os trechos que exigem uma correção, fornecendo ao aluno um texto correto. É importante ressaltar que, na maioria das vezes, o texto é correto de acordo com a perspectiva normativa da linguagem, muito atrelada ao contexto escolar.

Segundo Ruiz (1998), nas correções resolutivas as operações linguísticas como substituição, adição, supressão e deslocamento - típicas da reescrita - são empregadas pelo docente, não possibilitando ao aluno a oportunidade de refletir sobre e de realizar a reescrita de sua produção. Configura-se, portanto, como a categoria de correção que possui maior grau interventivo, uma vez que as revisões são caracterizadas como soluções para as inadequações presentes no texto, enquanto, nas outras categorias, são apenas dadas sugestões. No exemplo a seguir, uma correção resolutiva é realizada por um aluno revisor no texto de seu colega durante a oficina de fanfictions: 
FIGURA 3 - Revisão III

Depois de um tempo Desistidesisti de obter uma resposta dela e fui correndo para o meu quarto. Arrumei uma pequena mala com roupas suficientes para uma semana, precisava sair dali.

$\mathrm{Na}$ revisão III, o estudante revisor insere a expressão "Depois de um tempo" no início do parágrafo, de modo resolutivo, em vez de questionar seu colega sobre a incoerência da narrativa, podendo ter sugerido a marcação no texto de uma passagem de tempo, por exemplo. Assim, não foi possibilitado ao discente escritor pensar em uma alternativa que resolvesse a inadequação apresentada pelo revisor, visto que, nos casos em que a resolutiva é utilizada, o aluno escritor não tem direito de rever o que produziu, considerando que já recebe o texto refeito (GONÇALVES, 2007).

Torna-se evidente, a partir do exemplo apresentado, que na correção resolutiva o texto é reescrito por meio de soluções encontradas pelo revisor, e não pelo seu escritor, refletindo aquilo que o primeiro acredita que seja o melhor para determinada produção, conforme nos revela Serafini (1995). Para Gonçalves (2007), nesse tipo de correção o docente assume a linguagem do aluno como se fosse sua e, por isso, realiza as operações típicas da reescrita. Essa é mais uma evidência de que há uma tentativa do revisor de assumir o papel de escritor do texto ao reescrevê-lo, em vez de somente limitar-se a revisá-lo.

\subsubsection{A correção textual-interativa}

A revisão textual-interativa, por sua vez, foi teorizada por Ruiz (1998) como quarta categoria de revisão, tendo sido proposta como alternativa às três categorias criadas por Serafini (1995), isto é, a indicativa, a resolutiva e a classificatória.

$\mathrm{Na}$ textual-interativa, "bilhetes" são escritos pelo revisor ao escritor, sendo semelhantes a cartas (RUIZ, 1998), na medida em que podem possuir saudação inicial, despedida e, principalmente, interação explícita com o interlocutor por meio da materialidade linguística do texto. Ruiz ainda explica que tais bilhetes geralmente são escritos no "pós-texto", isto é, logo na sequência da produção do aluno ou em algum espaço "em branco" que foi obtido, considerando que são comentários mais longos do que os escritos na margem ou no corpo do texto. Contudo, reitero que o corpus da autora foi gerado em um contexto de produções escritas relacionadas ao modelo 
impresso. No contexto digital específico da oficina de fanfictions, a correção textual-interativa foi empregada pelos alunos por meio de comentários na forma de balões, sendo esse um recurso fornecido pela ferramenta de revisão do Word, conforme demonstrado no exemplo a seguir:

FIGURA 4 - Revisão IV

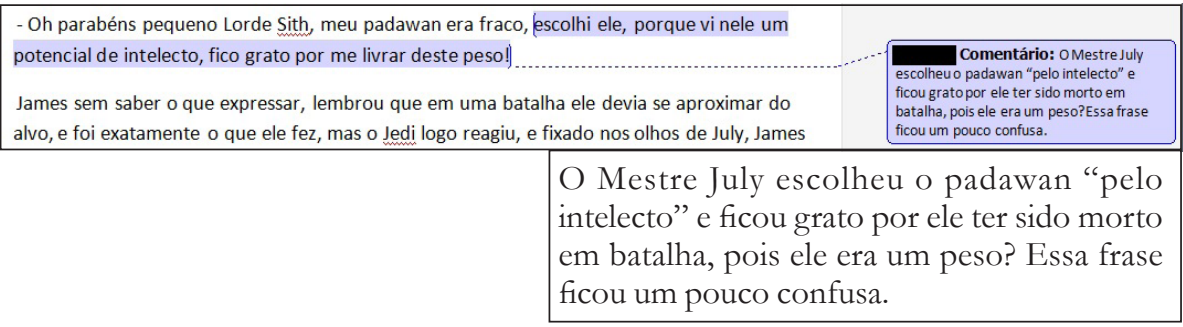

Em IV, o aluno revisor questiona o aluno escritor sobre a incoerência de um trecho de sua fanfiction e afirma que "essa frase ficou um pouco confusa”, fazendo uso da correção textual-interativa para tal, uma vez que escreve um comentário para seu interlocutor, isto é, seu colega. $\mathrm{Na}$ visão do discente revisor, não faz sentido a personagem "Mestre July" ter escolhido o seu padawan, mas, ao mesmo tempo, ficar grato por ele ter morrido. Assim, dirige-se ao seu interlocutor explicitando essa contradição na narrativa. Porém, a tarefa de encontrar alternativas na reescrita que possam solucionar este problema permanece sendo responsabilidade do escritor.

Nesse caso, as demais categorias - indicativa, resolutiva e classificatória - não se mostrariam satisfatórias, uma vez que nenhuma delas possibilitaria que o diálogo do revisor com o escritor fosse construído de forma mais explícita, marcada no texto. De acordo com Gonçalves (2007, p. 115), por meio da interação explícita com o interlocutor, "o estudante pode passar a considerar as implicações dialógicas do ato de escrever", embora a dialogicidade esteja presente em todas as categorias de revisão ao se considerar uma perspectiva bakhtiniana, conforme será discutido ainda neste artigo.

Além disso, de modo contrário à correção resolutiva, a textualinterativa tende a incentivar a prática de reescrita (RUIZ, 1998), pois geralmente proporciona ao aluno escritor a reflexão sobre seu texto, permitindo, também, que ele seja o responsável por pensar em alternativas para aquilo que foi apontado como inadequado pelo revisor. Assim, nem 
as soluções são realizadas na revisão, nem o texto chega já reescrito para o escritor. Na correção textual-interativa, é comum que sugestões e indagações sejam feitas ao escritor.

Portanto, segundo Ruiz (1998), o diálogo altamente produtivo entre escritor e revisor torna o texto e o trabalho com o texto em objetos do discurso. Essa categoria constrói-se a partir de uma atividade linguística que possui como objeto do discurso o dizer do escritor, e não apenas seu modo de dizer, como ocorre nas outras três correções que usualmente se concentram mais nos problemas linguísticos pontuais e superficiais do texto ligados à gramática normativa.

\subsubsection{A correção resolutiva/textual-interativa}

Ao analisar as quatro categorias de revisão em sua pesquisa, Ruiz (1998) chega à conclusão de que a correção resolutiva é a que apresenta caráter marcadamente monológico, diferenciando-se do caráter altamente dialógico das correções indicativa, classificatória e textual-interativa. De acordo com a autora,

tem sentido dizer que, apesar de o texto interventivo do professor que corrige ser, por princípio, dialógico [...], dependendo da forma que toma, esse discurso corretivo pode se apresentar como polifônico ou monofônico.

Segundo me parece, quando a correção se dá na forma resolutiva, o texto do professor é monofônico. Ao apresentar as alterações a serem aplicadas na reescrita, o discurso do professor anula totalmente a presença do outro (o aluno), que é, assim, destituído de voz. Tudo se passa como se o diálogo, constitutivo do próprio discurso do professor, estivesse oculto, escondido, mascarado sob a falsa aparência de uma única voz. Por outro lado, quando a correção se dá nas formas indicativa, classificatória, ou textual-interativa, ao contrário, o professor pressupõe explicitamente essa presença do outro em seu discurso, trazendo-o para dentro dele. [...] A voz do aluno/outro se mostra, se entrevê, revelando a perspectiva dialógica do discurso constitutivo do professor. Nesse sentido, seu texto é, pois, polifônico. (RUIZ, 1998, p. 104, grifo da autora)

Ruiz, em consonância com a teoria bakhtiniana, admite que todo enunciado é de natureza dialógica, mas afirma que, embora sejam dialógicos, podem apresentar caráter monológico, como é o caso dos enunciados 
produzidos a partir de correções resolutivas no corpus analisado por ela. Contudo, os dados analisados a partir das revisões realizadas para a oficina de fanfictions revelaram que outras interpretações acerca da correção resolutiva também são possíveis.

De acordo com Bakhtin (2011), cada enunciado deve sempre ser compreendido como uma resposta - em um sentido mais abrangente - a outros enunciados de um determinado campo, o que se relaciona com a natureza interdiscursiva da linguagem. Nesse sentido, "cada enunciado é pleno de ecos e ressonâncias de outros enunciados com os quais está ligado pela identidade da esfera de comunicação discursiva" (BAKHTIN, 2011, p. 297).

Tais ecos, ressonâncias, respostas e diálogos entre os enunciados são compreendidos a partir da teoria do dialogismo constitutivo da linguagem, do discurso e do texto. Para Bakhtin, o texto - contemplado neste trabalho como discurso - é o produto de uma criação ideológica, em cuja produção o contexto sócio-histórico e cultural influencia. Nessa perspectiva, a alteridade, isto é, o outro se torna imprescindível para a construção dos sentidos de um enunciado, e tanto a produção quanto a interpretação de um texto dependem da relação entre os sujeitos.

Todo enunciado, segundo Bakhtin, é dialógico na medida em que há construção de diálogos entre os interlocutores e também entre enunciados que já foram anteriormente produzidos. É considerando essa concepção que o autor afirma que "cada enunciado é um elo na corrente complexamente organizada de outros enunciados" (BAKHTIN, 2011, p. 272), pois se relaciona com aquilo que já foi proferido (isto é, enunciados que correspondem aos elos precedentes de uma cadeia), mas também com o que ainda será produzido (os elos que ainda serão construídos).

Assim, mesmo o enunciado que se caracteriza como um discurso individual e que tende ao monológico "nasce e se forma no processo de interação e luta com os pensamentos do outro" (BAKHTIN, 2011, p. 298) e, por isso, ainda assim é considerado dialógico.

Pessoa de Barros, partindo dos estudos de Bakhtin, afirma que o conceito de polifonia pode ser definido como um certo tipo de enunciado em que "são percebidas muitas vozes, por oposição aos textos monofônicos, que escondem os diálogos que os constituem” (BARROS, 2005, p. 34). A autora ainda explica que os textos monofônicos tendem a aparentar um discurso único e uma única voz, embora sejam de natureza dialógica. É nesse 
sentido que Ruiz (1998) compreende a correção resolutiva: um enunciado em que somente a voz e o discurso do professor, o revisor do texto do aluno, se fazem visíveis, uma vez que apresenta as resoluções prontas para o discente. Por isso, Ruiz considera tal categoria como sendo construída por enunciados monológicos.

Entretanto, nas revisões realizadas para a oficina de fanfictions, pude constatar que todas as categorias apresentaram caráter polifônico, inclusive a resolutiva, embora tal caráter tenha se revelado mais perceptível ao interlocutor nas situações em que a categoria observada e denominada por mim como resolutiva/textual-interativa foi empregada.

Vejamos um exemplo de correção resolutiva/textual-interativa para, em seguida, conceituar esta nova categoria:

FIGURA 5 - Revisão V

Enquanto Quandonão chegava ao meu destino, pensava sobre alguns fatos passados que passava em minha cabeça, como quando cheguei no 3 ano da genetics e como conheci meu limitador, Robert.

"Fatos passados que passavam" soou estranho. Que tal: "relembrava de alguns momentos", "recordava de quando..."

$\mathrm{Na}$ revisão $\mathrm{V}$, a aluna revisora fez uso da correção resolutiva ao sugerir o acréscimo das expressões "relembrava de alguns momentos" e "recordava de quando" no lugar da frase "fatos passados que passavam". Assim, a discente, na revisão, apresenta as soluções do problema apontado por ela enquanto revisora, em vez de instigar o estudante escritor a refletir, em sua reescrita, sobre aquilo que ela julga inadequado. Porém, ao mesmo tempo, a aluna revisora abre para o diálogo ao afirmar, a partir do emprego da correção textual-interativa, que "soou estranho", utilizando, ainda, a expressão "que tal", a qual alude a uma possibilidade ou sugestão, e não a uma imposição.

Assim, a correção resolutiva/textual-interativa consiste no emprego simultâneo das categorias resolutiva e textual-interativa em uma mesma revisão. Em outras palavras, essa categoria prevê que alternativas sejam apontadas pelo próprio revisor no momento da revisão, mas que sejam 
construídas como sugestões de mudanças no texto - sugestões estas realizadas por meio de uma interação explícita com o escritor na forma de um comentário - não havendo, assim, alterações diretas no texto.

Ao retornarmos à análise da revisão $\mathrm{V}$, é possível fazer uma comparação entre a correção resolutiva e a resolutiva/textual-interativa. Na primeira, a estudante revisora substitui a palavra "quando" por "enquanto" e elimina a expressão "em minha cabeça", sendo alterações realizadas diretamente no texto. De modo contrário, na segunda, a resolutiva é empregada em conjunto com a textual-interativa. Assim, a revisão deixa de se constituir como uma alteração na produção escrita do outro e passa a se posicionar na margem do texto, somente como uma sugestão de mudança. Embora o aluno escritor tenha a escolha de aceitar ou rejeitar ambas as correções realizadas, na resolutiva/textual-interativa essa opção se faz presente de modo mais evidente na maneira em que a revisão é realizada, como uma sugestão e não como uma imposição.

Nesse sentido, ainda que a reescrita desse trecho tenha sido efetuada pela própria revisora, não há sua imposição para o escritor, ao contrário: considera-se a presença do outro e, consequentemente, evidencia-se a sua voz. Desse modo, fica claro o caráter polifônico dessa categoria de revisão, por estar explicitada a voz do aluno escritor no enunciado do aluno revisor, mesmo que, em um primeiro momento, possa dar a impressão de se constituir como um enunciado monofônico.

Portanto, no contexto da oficina de fanfictions, foi possível constatar a natureza dialógica da revisão resolutiva de modo mais evidente nos casos em que houve o emprego da resolutiva/textual-interativa. Isso pode ter ocorrido considerando que a interação explícita com o aluno escritor por meio de bilhetes ou comentários pressupõe a presença do outro (o escritor/interlocutor) no discurso. Assim, essa nova categoria comprova que a correção resolutiva também apresenta indícios de caráter polifônico, já que, na perspectiva adotada neste artigo, todos os tipos de correção são compreendidos como dialógicos, embora a correção textual-interativa possibilite diálogos mais explícitos se comparada às outras.

É válido ressaltar que esses resultados podem ser decorrentes do uso da ferramenta de revisão de Word, por possuir o recurso da produção de comentários na margem do texto. As interações e os diálogos explícitos, portanto, puderam ser concretizados por meio da materialidade linguística dos comentários em forma de bilhete, tornando a natureza polifônica da 
resolutiva mais evidente ao interlocutor. Novamente, o contexto digital pode ter propiciado aos sujeitos o emprego das categorias de correção de um modo diferente daquele realizado no papel impresso.

\subsection{Uma apropriação da correção textual-interativa: leitores interessados}

Nesta terceira e última seção de análise, discuto sobre determinadas revisões presentes no corpus que empregaram a correção textual-interativa de modo muito particular, considerando o contexto da oficina de fanfictions. Para podermos compreender a apropriação que os sujeitos fizeram dessa categoria de correção, é preciso, primeiramente, situar a prática de revisão de fanfictions.

De acordo com Black (2005), é comum que os sites de produção e compartilhamento de fanfictions forneçam aos usuários ferramentas para que haja interação direta entre escritor/revisor/texto. Usualmente, comentários realizados em espaços destinados a esse fim cumprem com a função de iniciar e manter esse diálogo explícito ao longo da publicação dos capítulos das narrativas. Aliado a essa ferramenta, Black ainda nos mostra que os revisores, muitas vezes, posicionam-se também como leitores interessados nas histórias, revelando um entusiasmo genuíno pelas narrativas.

Tal posicionamento pode ser explicado ao considerarmos a situação de produção desse gênero: os revisores provavelmente são também fãs do universo ficcional que é usado como inspiração para a escrita da fanfiction. Assim, nessa conjuntura, acabam por expandir os papéis comumente exercidos na função, não se limitando a somente buscar uma melhoria no texto, por exemplo, mas revelando também impressões sobre a história.

Embora o corpus tenha sido gerado no ambiente escolar, ele constituiuse em uma oficina de produção de fanfictions que buscou se aproximar do contexto original de produção, isto é, os sites de compartilhamento online em que as fanfictions geralmente são publicadas. Assim, nos dados analisados, os revisores também se posicionaram como leitores interessados nos textos de seus colegas, caracterizando tais práticas como diálogos com enunciados do universo das fanfictions.

Portanto, comentários a respeito da narrativa foram realizados no momento da revisão, conforme pode ser observado nos seguintes exemplos: 
FIGURA 6 - Revisão VI

James Tnoy crescido à cerca de (mandalorianos, aprendeu a atirar com blasters, e alguns outros conceitos, e aos sete anos presenciou o Saque de Coruscant, efetuado com êxito por Darth Malgus, e assim, sabendo que os Sith haviam surgido novamente das trevas, pegou seus pertences e foi voltar para Drommund Kaas, planeta no qual saiu por decisões superiores.

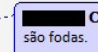
são fodas. Mandalorianos são fodas.

FIGURA 7 - Revisão VII

A menina morena era chamada Claire. E era minha namorada. Digo, (ela era a namorada de Avelyn.

Comentário: PeraíxD Elas são lésbicas?? XD

Tanto em VI quanto em VII, a correção textual-interativa foi empregada como meio de interação explícita entre os estudantes revisores e os escritores. No primeiro caso, o discente registrou sua opinião em relação a uma espécie criada na saga cinematográfica de Star Wars e que foi retomada na fanfiction do colega. Ao afirmar que "Mandalorianos são fodas", o revisor fez uso de uma gíria para elogiar as habilidades de luta dessa espécie. Já no segundo caso, a aluna revisora revela estar surpresa ao perceber que duas personagens femininas da história mantinham uma relação amorosa: "Peraí XD Elas são lésbicas?? XD".

Considerando as funções de um revisor, era esperado que nas revisões VI e VII o conteúdo dos comentários fosse relacionado a sugestões de melhorias do texto, das convenções da escrita, do andamento da narrativa ou da adequação ao gênero, entre outros aspectos. Porém, os alunos decidiram escrever aquilo que julgaram pertinente deixar registrado enquanto leitores que são da história, caracterizando-se como uma espécie de feedback que um leitor forneceria a uma obra. Partindo dessa perspectiva, o uso da textual-interativa é justificado, já que é a única dentre as quatro categorias de correção que permite a interação e o diálogo explícitos entre interlocutores por meio da elaboração de comentários na forma de bilhete.

A ferramenta de revisão do Word, nesses casos, não foi utilizada para revisar o texto, assim como a textual-interativa não objetivou corrigir ou apontar determinada inadequação. Ao contrário, ambas ferramenta e categoria de correção foram empregadas com funções diferentes daquelas previstas originalmente, isto é, meio e modo de revisão, respectivamente. 
Assim, nos dados apresentados os estudantes revisores realizaram comentários - por meio da correção textual-interativa - com o intuito de somente fornecer suas impressões em relação às narrativas. Permitiram-se, portanto, ir além de seu papel de revisor, posicionando-se também como leitores no mesmo momento em que estavam revisando as narrativas de seus colegas.

\section{Considerações finais}

O objetivo deste trabalho é refletir sobre a apropriação da prática de revisão textual feita por alunos em uma oficina de fanfictions realizada no contexto escolar. Portanto, para estas considerações finais, apresento uma síntese das análises realizadas na seção 3 do artigo:

a) A função da correção indicativa, no contexto digital, revelou-se diferente quando comparada ao contexto do modelo impresso. Na situação de produção da oficina de fanfictions, a correção indicativa foi incorporada às demais categorias de correção, isto é, em todas as revisões em que a classificatória, resolutiva, textual-interativa e resolutiva/textual-interativa foram utilizadas, houve, em conjunto, emprego da indicativa. Assim, essa categoria teve como função auxiliar na localização e visualização da revisão realizada no texto, sendo uma apropriação que os sujeitos fizeram dos recursos presentes na ferramenta de revisão do Word. Como conclusão, pude constatar que o instrumento utilizado na revisão também é um fator que interfere no modo como a prática é realizada e a categoria de correção, empregada.

b) A correção resolutiva/textual-interativa, nova categoria observada a partir do corpus das revisões realizadas para a oficina de fanfictions, explicitou o caráter polifônico da correção resolutiva. Considerando que a correção resolutiva/textual-interativa apresenta, em uma mesma revisão, traços característicos das correções resolutivas e textualinterativa (como o próprio nome sugere), era previsto que o caráter monológico da resolutiva prevalecesse. Contudo, nessa categoria as alternativas propostas pelo revisor foram expostas - por meio de um comentário - como sugestões de alteração no texto, diferentemente das mudanças diretas no texto, previstas pela resolutiva. Desse modo, embora esteja claro que a textual-interativa é a categoria em que é mais visível o caráter dialógico do discurso, a análise das correções resolutivas/textual-interativas comprovou que até a resolutiva é também polifônica. 
c) $\mathrm{O}$ uso da correção textual-interativa pelos sujeitos revisores que se posicionaram como "leitores interessados" revelou uma nova função para a categoria e para a ferramenta, ambas associadas à situação de produção do gênero fanfiction. Os alunos fizeram uso da ferramenta de revisão do Word e da correção textual-interativa com o intuito de comentar sobre a narrativa, fornecendo um feedback ao escritor, tal como um leitor o faria. Não se objetivou, portanto, revisar o texto nas situações em que esse tipo de comentário foi escrito. Nesse sentido - ao contrário da análise realizada na letra 'a' destas considerações finais -, no caso das correções feitas pelos "leitores interessados", foi a prática (de escrita, revisão e reescrita de fanfictions) que se revelou como fator de interferência e constituição no modo como o instrumento (a ferramenta do Word) é utilizado pelos sujeitos desta pesquisa, e na maneira como a categoria de correção é empregada, modificando até mesmo a sua função.

A partir da análise desses três aspectos referentes às revisões realizadas no decorrer da oficina, acredito que a prática de revisão no ambiente escolar possa ser repensada ao serem levados em conta os usos e as apropriações que os alunos fizeram das categorias de correção, do instrumento de revisão (ferramenta do Word) e também da prática de escrita de fanfictions no contexto escolar.

É considerando essas discussões que afirmo que este artigo pode apresentar uma alternativa, entre muitas possíveis, para refletirmos sobre a prática de revisão escolar. A ideia de os alunos revisarem e terem seus textos revisados por um colega, por exemplo, possibilitou que eles, enquanto sujeitos revisores, ocupassem a posição de leitores interessados e, além disso, considerassem o estudante escritor como um interlocutor autêntico, evidenciando as vozes dialógicas de todo e qualquer discurso.

\section{Agradecimentos}

Agradeço os apontamentos realizados pela professora doutora Ângela Francine Fuza durante a defesa da dissertação, que muito auxiliaram para a produção deste artigo. Gostaria de agradecer também à professora doutora Raquel Salek Fiad pelas sugestões feitas durante a leitura da primeira versão do texto. Por fim, agradeço ao CNPq por ter concedido apoio financeiro para a realização desta pesquisa. 


\section{Referências}

ANDRÉ, M. E. D. A. Estudo de caso em pesquisa e avaliação educacional. Brasília: Líber Livro Editora, 2005.

BAKHTIN, M. M. Os gêneros do discurso. In: - Estética da criação verbal. Trad. Paulo Bezerra. 6. ed. São Paulo: Editora WMF Martins Fontes, 2011. p. 261306.

BARROS, D. L. P. Contribuições de Bakhtin às teorias do discurso. In: BRAIT, B. (Org.). Bakbtin, dialogismo e construção do sentido. Campinas: Editora da UNICAMP, 2005. p. 25-36.

BLACK, R. Access and affiliation: the literacy and composition practices of English-language learners in an online fanfiction community. Journal of Adolescent \& Adult Literacy, Hoboken, v. 49, n. 2, p. 118-128, 2005. Disponível em: <https:// bit.ly/2ya8W05>. Acesso em: 14 jun. 2018.

BLACK, R. Language, culture, and identity in online fanfiction. E-Learning, Thousand Oaks, v. 3, n. 2, p. 170-184, 2006. Disponível em: <https://bit. ly/2LRHwy1>. Acesso em: 14 jun. 2018.

BLACK, R. Just don't call them cartoons: the new literacy spaces of anime, manga, and fanfiction. In: COIRO, J.; KNOBEL, M.; LANKSHEAR, C. LEU, D. J. (Org.). Handbook of research on new literacies. Mahwah: Erlbaum, 2008. p. 587-615.

BLACK, R. Online fan fiction and critical media literacy. Journal of Computing in Teacher Education, Eugene, v. 26, n. 2, p. 75-80, 2010. Disponível em: < https:/ / bit. ly/2HO5IyS>. Acesso em: 14 jun. 2018.

CHIZZOT'TI, A. Pesquisa qualitativa em ciências humanas e sociais. 2. ed. Petrópolis: Vozes, 2008.

CONCEIÇÃO, R. I. S. Correção de texto: um desafio para o professor de português. Trabalhos em Linguistica Aplicada, Campinas, v. 43, n. 2, p. 323-344, 2004. Disponível em: < https://bit.ly/2JGeSDl>. Acesso em: 14 jun. 2018.

FIAD, R. S. Escreveré reescrever: caderno do professor. Belo Horizonte: Ceale/FaE/ UFMG, 2006.

GONÇALVES, A. V. Gêneros textuais e reescrita: uma proposta de intervenção interativa. 2007. 343f. Tese (Doutorado em Linguística e Língua Portuguesa) Faculdade de Ciências e Letras, Universidade Estadual Paulista "Júlio de Mesquita Filho", Araraquara, 2007. 
GONÇALVES, A. V. Gêneros textuais e reescrita: uma proposta de intervenção para o ensino de língua materna. Linguagem em (Dis)curso, Palhoça, v. 10, n. 1, p. 13-42, 2010. Disponível em: <https://bit.ly/2lcJtKa>. Acesso em: 14 jun. 2018.

GONÇALVES, A. V.; BAZARIM, M. (Org.). Interação, gêneros e letramento: a (re) escrita em foco. 2. ed. Campinas: Pontes Editores, 2013.

JENKINS, H. Textualpoachers: television fans and participatory culture. New York: Routledge, 1992.

JENKINS, H. Convergence culture: where old and new media collide. New York: NYU Press, 2006.

LÜDKE, M.; ANDRÉ, M. E. D. A. Pesquisa em educação: abordagens qualitativas. São Paulo: EPU, 1986.

MENEGASSI, R. J. Professor e escrita: a construção de comandos de produção de texto. Trabalhos em Linguística Aplicada, Campinas, v. 42, n. 2, p. 55-79, 2003. Disponível em: < https://bit.ly/2JPJ1fK>. Acesso em: 14 jun. 2018.

MENEGASSI, R. J. O interlocutor nas propostas de produção textual no livro didático. Trabalhos em Linguistica Aplicada, Campinas, v. 50, n. 1, p. 169-187, 2011. Disponível em: <https://bit.ly/2JBOlXP>. Acesso em: 14 jun. 2018.

RUIZ, E. M. S. D. Como se corrige redação na escola. 1998. 307f. Tese (Doutorado em Linguística) - Instituto de Estudos da Linguagem, Universidade Estadual de Campinas, Campinas, 1998.

SARTORI, A. T.;MENDES, L. Z. A reescrita como processo: as vantagens de uma segunda versão tardia. Revista do GEL, Assis, v. 13, n. 3, p. 130-157,2016. Disponível em: < https:// bit.ly/2ybhR1v>. Acesso em: 14 jun. 2018.

SERAFINI, M. T. Como escrever textos? 7. ed. São Paulo: Globo, 1995.

THIOLLENT, M. Metodologia da pesquisa-ação. 18. ed. São Paulo: Cortez, 2011.

Data de submissão: 30/05/2017. Data de aprovação: 24/05/2018. 